\title{
ERRATUM
}

\section{Slumps and Jumps: Another Look at Developmental Changes in Creative Abilities}

Jacek Gralewski

The Maria Grzegorzewska University, Poland

E-mail address: jacekgralewski@ 02.pl

\section{Aleksandra Gajda}

The Maria Grzegorzewska University, Poland

E-mail address: agajda@aps.edu.pl

\section{Ewa Wiśniewska}

The Maria Grzegorzewska University, Poland

E-mail address: ewawisniewska@aps.edu.pl
Izabela Lebuda

The Maria Grzegorzewska University, Poland

E-mail address: izalebuda @aps.edu.pl

Dorota M. Jankowska

The Maria Grzegorzewska University, Poland

E-mail address: dorotamariajankowska@gmail.com

\section{ARTICLE INFO}

ISSN: 2354-0036

DOI: 10.1515/ctra-2017-0009

\section{Erratum}

1. Cited reference details:

Gralewski, J., Lebuda, I., Gajda, A., Jankowska, D., and Wiśniewska, E. (2016). Slumps and Jumps: Another Look at Developmental Changes in Creative Abilities. Creativity. Theories - Research - Applications. Volume 3, Issue 1, pages 152-177.

2. DOI of original article: DOI: 10.1515/ctra-2016-0011

3. Description of the changes:

\begin{tabular}{lll}
\hline Place & Description of the change (error) & The change itself (valid notation) \\
\hline Title page & The incorrect e-mail address: & \\
& $\begin{array}{l}\text { Dorota M. Jankowska } \\
\text { The Maria Grzegorzewska University, }\end{array}$ & Dorota M. Jankowska \\
& The Maria Grzegorzewska University, \\
& Eoland & Poland \\
& E-mail address: & E-mail address: \\
djankowska@ aps.edu.pl & dorotamariajankowska@gmail.com
\end{tabular}

Abstract The incorrect sample size:

A large and diversified sample of Poles ( $N=4898$ aged from 4 to 21 years), ...

A large and diversified sample of Poles ( $N=4854$ aged from 4 to 21 years), ... 


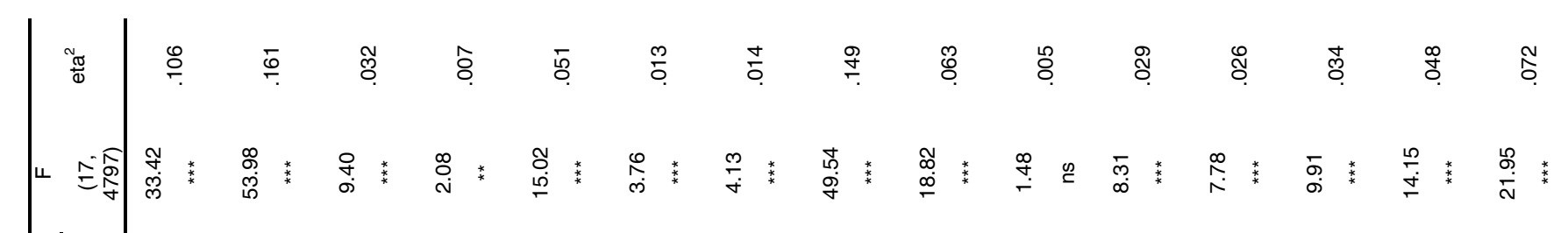

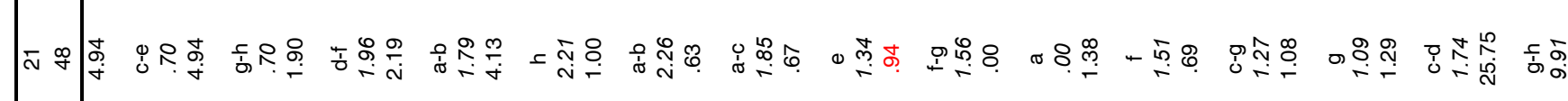

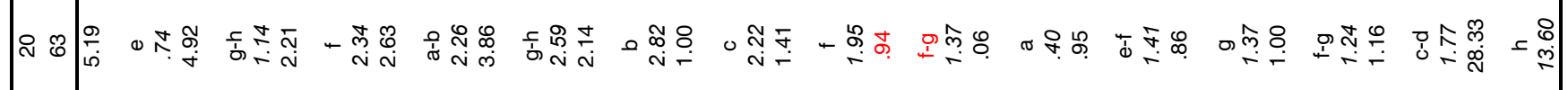

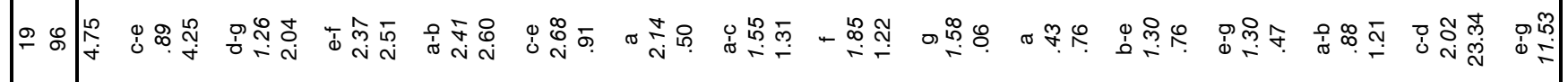

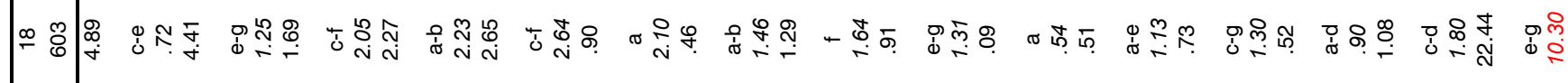
=

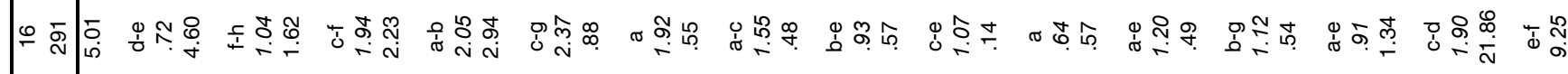
岂

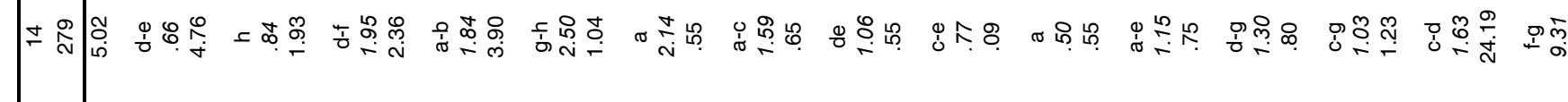
事

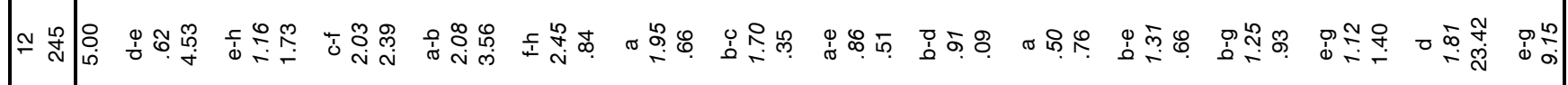

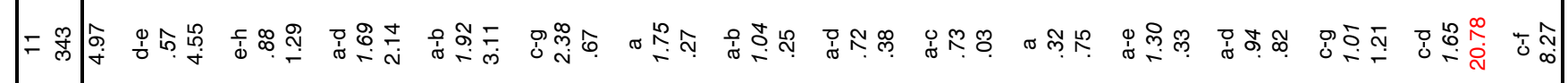
员 旁

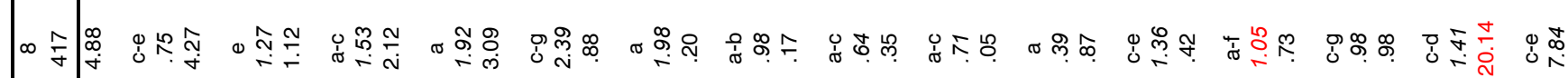
人 స̂N ○ 巟侻 以

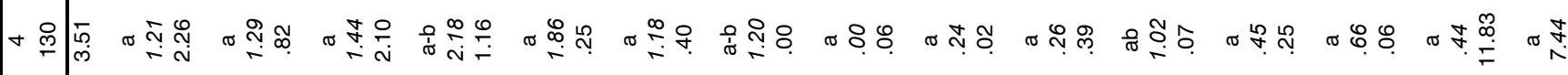
$\Sigma$ के $\Sigma$ के $\Sigma$ के $\Sigma$ के $\Sigma$ के $\Sigma$ के $\Sigma$ के $\Sigma$ के $\Sigma$ के $\Sigma$ के $\Sigma$ के $\Sigma$ के $\Sigma$ के $\Sigma$ के $\Sigma$ की z

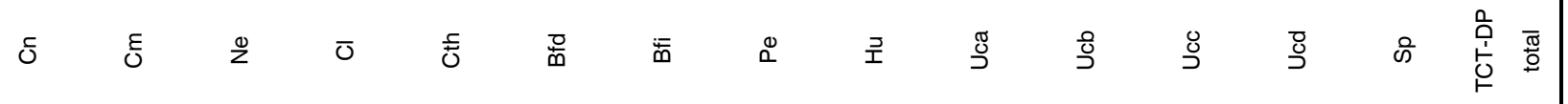

